\title{
Empowerment and Privacy? Home Use of Abortion Pills in the Republic of Ireland
}

Surely, I find myself day-dreaming, there is something, some substance already in common use, that women could drink after sex or at the end of the month, that would keep them unpregnant with no one the wiser. Something you could buy at the supermarket, or maybe several things you could mix together, items so safe and so ordinary they could never be banned, that you could prepare in your own home, that would flush your uterus and leave it pink and shiny and empty without you ever needing to know if you were pregnant or about to be. A brew of Earl Grey, Lapsang souchong, and ground cardamom, say. Or Coca-Cola with a teaspoon of Nescafé and a dusting of cayenne pepper. Things you might have on your shelves right now, just waiting for some clever person to put them together, some stay-at-home mother with a chemistry degree rattling around her kitchen late at night.

-Katha Pollitt $(2014,4-5)$

M

ore than a century of political struggle has failed to achieve unfettered access to safe, early, confidential abortion across most of the world. What if that possibility could be carried quietly and unceremoniously through the back door in grocery bags? The control of one's own fertility would become a concrete possibility, with that control firmly located in women's own hands. Abortion would become a truly private matter. Laws that criminalize ending pregnancies would become unenforceable, falling into desuetude. Unsafe abortion would become a thing of the past wherever

I am grateful to the UK Arts and Humanities Research Council for funding this research $(\mathrm{AH} / \mathrm{L} 006537 / \mathrm{l})$ and to those people who shared their knowledge and insights in interviews. Thanks also to my advisory group: Jennie Bristow, Joanna Erdman, Ruth Fletcher, and Patricia A. Lohr, for valuable feedback and support throughout the research; to Máiréad Enright and three anonymous reviewers for their enormously helpful and constructive comments on an earlier draft of this article; and to Miranda Outman and Katherine Fleming for their careful and skilled editorial work. For further information and details of other project publications, see: http://www.kent.ac.uk/law/mabal/index.html.

[Signs: Journal of Women in Culture and Society 2018, vol. 43, no. 4]

(C) 2018 by The University of Chicago. All rights reserved. This work is licensed under a Creative Commons Attribution-NonCommercial 4.0 International License (CC BY-NC 4.0), which permits noncommercial reuse of the work with attribution. For commercial use, contact journalpermissions@press.uchicago.edu. 0097-9740/2018/4304-0003\$10.00 
those few, cheap ingredients and the knowledge of how to combine them were available. That knowledge would, inevitably, spread quickly through communities. Tens of thousands of deaths and millions of injuries due to unsafe abortion (WHO 2011) might potentially be prevented each year.

Early reports heralded the development of mifepristone (then known as RU486) as promising a similarly dramatic reproductive revolution. For its developer, mifepristone was "a contragestive" or "unpregnancy pill" (Baulieu 1991, 18) that would operate safely and effectively, early after conception. As mifepristone became widely available, others predicted that it would "change everything" (Time 1993), with the "seemingly intractable" abortion debate thus reaching its "unceremonious solution" (Cole 1989, 217). ${ }^{1}$ The question of how a state should regulate access to abortion would simply become irrelevant, as abortion pills firmly and irrevocably located control of women's fertility in the hands of women themselves. After all, "how can a state control swallowing?" (Goodman 1989, 11). While there is nothing new about large numbers of women disobeying restrictive abortion laws (e.g., McLaren 1978; Kaplan 1995), the promise of abortion pills was that they might enable women to do so safely and effectively in their own homes, with no need for particular expertise, specialist equipment, or significant assistance from others.

Some twenty-five years later, I assess the extent to which abortion pills have fulfilled such predictions, focusing on their use in a country with notoriously restrictive abortion laws: the Republic of Ireland. I do not engage with debates regarding the ethics of abortion but begin with two premises: first, that control of one's own fertility is a basic human right and, second, that there is an overwhelmingly strong public health rationale for access to safe, legal abortion (WHO 2012, chap. 1). With these assumptions in place, I consider the potential of abortion pills to deliver a safe, effective, private means of early abortion that allows women to seize control of their own fertility, in a context where that right has been denied them. I focus, in particular, on the potential of the pills to deliver empowerment and privacy, goals that operate in close tandem in the vision offered above and, as will be seen below, intersect in complex ways in practice.

I begin with some brief context regarding the home use of abortion pills in Ireland, focusing in particular on the work of two online collectives, Women on Web (WoW) and Women Help Women (WHW), which work closely with local activists to support women facing unwanted pregnancies, including through the supply of abortion pills. I consider, first, the extent to which the availability of abortion pills has empowered both individuals and communities of women with the promise of a private, home abortion. I

\footnotetext{
${ }^{1}$ See also Baulieu (1991), Lader (1992), Clarke and Montoni (1993), and Bass (1998).
} 
then explore the limitations of illegal home use as a panacea for deficiencies in domestic service provision. In particular, I highlight how readily privacy collapses into secrecy, with practices of nondisclosure around abortion operating not merely to facilitate and sustain individual empowerment but also as an important brake upon it. Moreover, I suggest, widespread practices of nondisclosure serve to distort public debate and to obscure the harm done by punitive criminal laws, fueling a cultivated state ignorance that serves to obscure responsibilities for promoting and protecting women's reproductive health (McAvoy 2008; Culhane 2015; see further Sherlock 2015).

Throughout, I draw on information collected from twenty-two factfinding interviews conducted with abortion support groups, activists, government officials, counseling service providers, and doctors in 2015. The manner in which each interviewee is identified (either by first or last name or just by role description) was determined in consultation with each individual concerned. Each interviewee was given the opportunity to approve or amend quotations prior to publication.

\section{Ireland's abortion law}

The Republic of Ireland has been subject to repeated condemnation for violating women's human rights in the context of abortion law (e.g., recently, UNHRC 2016; Amnesty International 2015). In 1983, the Eighth Amendment to the Irish Constitution was introduced. This accords the "right to life of the unborn" equal weight to that of the "mother" and commits the Irish state to defending and vindicating that right (see generally Schweppe 2008). ${ }^{2}$ The 2013 Protection of Life during Pregnancy Act provides that abortion is generally punishable by a fourteen-year prison term for both the person who undergoes the abortion and the person who performs it but confirms that an abortion may be carried out legally to save a woman's life. Abortion is lawful only where two doctors (or three where the risk results from suicidality) agree that there is "a real and substantial risk to a woman's life" that can be averted only by carrying out "the medical procedure." ${ }^{\prime 3}$ The harshness of the law was illustrated in the widely reported case of Ms. Y, a newly arrived refugee who was pregnant by rape and threatening suicide if forced to continue her pregnancy. Ms. Y requested an abortion at eight weeks of pregnancy. The panel that considered her request eventually reached a decision at twenty weeks, refusing an abortion but recommending that she be "treated" at twenty-five weeks by way of caesarean section. The grounds for refusing an abortion apparently relied on the judg-

${ }^{2}$ Article 40.3.3, Bunreacht na hÉireann (the Constitution of Ireland).

${ }^{3}$ Ibid., see secs. 7 and 9. 
ment that it was reasonable to perform such surgery on a woman against her wishes in order to preserve the life of the fetus (Fletcher 2014, 13). Ms. Y's case offers a powerful demonstration of the potentially devastating impact of Irish law on women denied access to abortion services.

More recently, there have been clear indications that Irish abortion law may be subject to change in the near future. Following the General Election of 2016, in which abortion was a significant issue, the government established a Citizens' Assembly, which was charged with considering the need for legal reform in a range of areas, including abortion law. The assembly was chaired by a Supreme Court judge and brought together ninety-nine citizens selected by a polling company (Citizens' Assembly 2017, 43). Having met over five weekends to consider evidence from a range of sources, the assembly went on to vote in favor of removing the Eighth Amendment from the Constitution, leaving it to the Oireachtas (the Irish Parliament) to decide how to legislate on abortion. The assembly also made specific recommendations as to what should be included in such legislation, with 64 percent of members agreeing that the termination of pregnancy should be lawful without restriction within prescribed time limits (Citizens' Assembly 2017, 9).

In the light of the assembly's recommendations, Leo Varadkar, the Irish Taoiseach (prime minister) has committed to holding a further referendum in summer 2018 on whether the Constitution should be changed (McDonald 2017). The exact wording of the proposition that will be put to a vote is yet to be determined at the time of this writing. If the referendum results in a vote in favor of repealing the Eighth Amendment, there would then need to be a process of statutory reform to amend the 2013 Act; consensus regarding what might replace it is likely to prove elusive. As such, the path to a meaningful change in Irish abortion law appears set to be a lengthy and difficult one, with the issues considered in this article likely to remain real and pressing in the near future.

While only twenty-six abortions were reported within Irish health services in 2014 (Ryan 2015), it is impossible to know how many women felt forced to continue unwanted pregnancies and how many chose to end them outside formal domestic health care services. However, international data shows that restrictive abortion laws often coexist with very high rates of abortion (Sedgh et al. 2016). In the case of Ireland, women frequently access services in England, with rights to information and to travel to access abortion services abroad written into the Irish Constitution. However, accessing services overseas is an option only for those with the necessary legal documentation (passport, visa) and the estimated $€ 450-€ 2,500$ (US\$530-\$2,920) necessary to fund the procedure, travel, and accommodation (ASN 2014). Finding such a sum can cause very real hardship, exposing women to consider- 
able risks, particularly where a concern for secrecy leads to recourse to unregulated backstreet moneylenders. Alternatively, women may find themselves unable to pay for electricity or groceries as they are forced to divert scarce resources. ${ }^{4}$ Further, the need to travel can cause significant problems in terms of rearranging child care or work commitments.

Finally, women may attempt, illegally, to end their pregnancies within Ireland but outside of formal health services. The Abortion Support Network (ASN) offers advice and practical support to Irish women facing unwanted pregnancies. It reports contacts from women who have drunk bleach or floor cleaner in an effort to provoke a miscarriage and from one who told them quite matter-of-factly: "I'm trying to figure out how to crash my car to cause a miscarriage but not permanently injure myself or die." However, a far greater number of women use abortion pills.

\section{The home use of abortion pills within Ireland}

\section{The extent of home use}

The official recorded numbers of women who reside in Ireland and access abortion services in England are unreliable, in that some women may give false addresses. Nonetheless, they show a trend that is so marked as to suggest real and significant change, coming close to halving over the past fifteen years. The drivers of this dramatic fall-from 6,672 in 2001 to 3,451 in 2015 (ONS 2002; Department of Health 2016) - are likely multiple (Sheldon 2016). However, the illegal home use of abortion pills has undoubtedly contributed substantially to it. An internet-literate population will quickly discover the many websites where abortion pills can be accessed online. There were over fifty thousand searches for self-induced abortion methods across all search engines within Ireland in 2015, with two-thirds of those searches relating to abortion pills. ${ }^{6}$

Two nonprofit groups have played a particularly important role in offering support to women seeking access to abortion pills: Women on Web and Women Help Women. Strongly motivated by values of social justice and solidarity (Prainsack and Buyx 2011), each offers advice and practical support by email, including supply of abortion pills to countries where abortion is illegal. Each group works closely with local activists, who help to facilitate supply and to spread awareness of abortion pills through a range of means,

${ }^{4}$ Interview with Mara Clarke, director of the Abortion Support Network.

${ }^{5}$ Ibid.

${ }^{6}$ Cate Russell, "Self-Induced Abortion Searches: An Initial Analysis of Google Data." Unpublished manuscript on file with the author. 
including posters, stickers on toilet doors, and publicity stunts - such as driving an "abortion bus" around Irish towns (Hayden 2015) — designed to publicize the groups' websites.

WoW has recently published data regarding the women on the island of Ireland (including both the Republic and Northern Ireland) who access their services (Aiken, Gomperts, and Trussell 2017). Between January 1, 2010 , and December 31, 2015, 5,650 women requested abortion pills, with the numbers more than doubling across that period. Some 1,438 women were treated in 2015. On the basis of their respective populations, it is reasonable to assume that over one thousand of these women were in the Republic. The more recently established WHW prefers not to share the number of pills supplied, emphasizing that it is the number of requests for help that illustrates the true extent of the need. However, they reported "daily contacts" from across the island of Ireland, suggesting that they also supply pills to a significant number of women in the Republic. ${ }^{7}$ Beyond these two groups, women are also attempting to access pills from other sources. Sixty consignments of abortion pills impounded by Irish Customs in 2014 clearly originated from other suppliers, as WoW and WHW refuse to ship directly to Ireland, with women generally asked to provide an address elsewhere of someone who can either forward the pills or hold them for the woman to collect. ${ }^{8}$ It is impossible to know what proportion of consignments evade detection and, further, the extent of any domestic black market in the pills. While the exact numbers of women who use abortion pills are unknown, there are thus clear indications that they are significant.

\section{The safety of home use}

A substantial clinical literature suggests strong grounds for believing that the online services offered by WoW and WHW are very safe and likely to be highly acceptable to women, particularly when compared to the alternatives available (Sheldon 2016). In interviews, this was confirmed by local activists who are in contact with the women who use the pills. Telemedical protocols are growing more common within national health services (Grossman et al. 2011; Wiebe 2013; Jabour 2015), and peer-reviewed studies confirm the safety and acceptability of WoW's service (Gomperts et al. $2008,2011)$. Almost all of the women who had accessed abortion pills from WoW and were included in the above survey felt that home use of pills had

\footnotetext{
${ }^{7}$ Interview with founding member, WHW.

${ }^{8}$ Customs seizures data obtained by Ruth Coppinger, Teachta Dála (lower house of Irish Parliament). Information on shipping practices obtained in interviews with WHW and WoW.
} 
been the right choice (97 percent) and one that they would recommend to another woman (98 percent; Aiken, Gomperts, and Trussell 2017).

WoW and WHW are strongly committed to the well-being of the women who use their services. Each organization supplies abortion pills for use within the first nine weeks of pregnancy, after completion of an online questionnaire that screens for contraindications. They follow a common treatment protocol of oral mifepristone and, after twenty-four hours, sublingual misoprostol. While my interviews were conducted only with service providers and activists, rather than with women who had used the pills, these revealed no evidence that women struggle to follow the simple instructions. In interviews, I was given just one example of incorrect use: a woman who, desperate at finding herself pregnant as a result of rape, had been given pills by an activist, without the involvement of WoW or WHW. She was then believed simply to have swallowed everything at once. ${ }^{9}$ While this posed no significant risk to her health, she needed a second course of medication in order to end an ongoing pregnancy. For the activist who shared this story, it illustrated the importance of women having direct personal contact with WoW or WHW, so that they always receive clear and accurate information regarding correct use.

Mifepristone and misoprostol are both listed in the World Health Organization guide to essential medicines (WHO 2015b) and can be safely supplied by appropriately trained and skilled nondoctors (WHO 2012; 2015a). Where correctly used, the pills are effective in over 95 percent of cases (Raymond et al. 2013; see also Kulier et al. 2011; Cleland and Smith 2015). Few women experience serious side effects or complications as a result of their use, with pain generally manageable with over-the-counter analgesics. However, in a small number of cases (fewer than two in 1,000 ), serious adverse events, such as excessive bleeding or infection needing treatment with intravenous antibiotics, can occur (Kulier et al. 2011; Cleland et al. 2013; Cleland and Smith 2015). WoW and WHW both advise women to determine in advance which local hospital they would attend if that becomes necessary. In interviews, they emphasized that such forward planning makes an induced miscarriage considerably safer than when a miscarriage occurs spontaneously. Only one interviewee, from neighboring Northern Ireland, which has a similarly restrictive law and where there are also strong indications that the pills are in widespread use, reported any knowledge (albeit secondhand) of a woman suffering serious health complications as a result of the use of the pills. The former director of the Family Planning Association in Northern Ireland (FPANI), Audrey Simpson, had been contacted by

${ }^{9}$ Interview with anonymous activist. 
a doctor who reported treating a woman suffering from "life-threatening" problems after taking abortion pills. The doctor (erroneously) believed that the woman had been advised on how to access the pills by the FPANI and threatened to inform the police if the same thing happened again. ${ }^{10}$ No further details were available.

There is at least a hypothetical risk that heightened stigma regarding illegal abortion and fear of prosecution might lead to a reluctance to seek necessary aftercare. One doctor cited in a study of Irish general practitioners' attitudes to abortions reported a patient who had suffered "significant complications requiring hospitalization" following use of abortion pills but had initially refused hospital treatment as her intimate partner was a medical professional, and she feared the "ramifications of discovery" (Murphy et al. $2012,141)$. However, none of my interviewees had experience or knowledge of women failing to seek medically necessary aftercare, and none believed that this was likely to happen. Several emphasized how careful women were of their own health, and one noted that exaggerated claims regarding the dangers of abortion pills in the media and official guidance-discussed below-had contributed to extreme vigilance regarding any indication of a need to seek further medical care. ${ }^{11}$

\section{Empowerment and privacy}

\section{Individual women}

"Empowerment" may be defined as a process that helps people to gain control over their own lives and foster power for use in their lives, their communities, and their society (Page and Czuba 1999). Abortion pills can serve to empower women, with significant echoes of the pro-choice vision with which I opened. One woman treated by WoW wrote to thank them "for enabling women to have control over their bodies," with another explaining that the service had given her "another chance to continue my personal battle as a single mother to create a good quality of life for my child, working hard in three jobs to make ends meet and create opportunities and potential for her future" (Aiken, Gomperts, and Trussell 2017, 1212).

With abortion pills, a woman's control of her own fertility is quite literally in her own hands. This is also true when pills are used legally, problematizing any tendency to describe just those terminations that occur outside of formal health facilities as "self-administered"; "independent"; or, in the

\footnotetext{
${ }^{10}$ Interview with Audrey Simpson, director of FPANI.

${ }^{11}$ Interview with Kinga Jelinska, director of WHW
} 
characterization of the popular media, "DIY abortions." Regardless of how the pills are accessed, women may then place them in their own bodies, monitor their own miscarriages, treat pain with mild analgesia as they judge necessary, confirm that the abortion is complete, and identify the symptoms that mean further medical care is necessary. While in this article I use the phrase "home use" to distinguish those terminations that are self-induced illegally from those offered legally in clinics or hospitals, this too may be deceptive. In many parts of the world, the law permits women to be given pills to take at home. Caution is also needed in attempting to distinguish between "supervised" and "unsupervised" use. This change in the technology of abortion decenters the role of the medical expert, with the level of supervision foreseen in different service provision models best seen as operating along a continuum. At one end lies tightly supervised use within a hospital or clinic, with pills prescribed following a screening and consultation and the woman remaining on site until her miscarriage is confirmed as being complete. At the other lies the purchase of pills for home use from an unknown internet supplier, with no prior screening or consultation, limited or no information as to correct use or how to recognize potential complications, and no further support. WoW and WHW's service lies between these two extremes. Each group relies on clinical evidence and, at times, on medical expertise. They follow clinical trial treatment protocols, screen for recognized contraindications, and offer detailed and accurate medical information on their websites. However, each also offers more control to (and demands more responsibility of) individual women than is the case with many other abortion services.

First, women are trusted to report how advanced their pregnancies are, with pills supplied only for use within the first nine weeks of pregnancy. Each group emphasized that women generally seek help early, with contacts beginning from when a period is one day late. ${ }^{12}$ However, each had also experienced a small number of cases where women had given false information in order to access pills. In those instances, they saw it as their responsibility to give neutral information regarding what a woman might expect were she to use the pills and, thus, how she could prepare herself emotionally and keep herself safe:

We do get women who write and say that they are actually later than nine weeks. ... Those women have to be counseled very differently. They use a different dose of the medicine. But it's not that the risks are much greater, it's more that she has to be psychologically prepared

${ }^{12}$ Interview with Maike, member of the help desk staff, WoW. 
for the process - this [the products of conception] isn't going to end up going down the toilet or on a menstrual pad. So it's about informing her before she takes the medicine, so that she makes an informed decision. ${ }^{13}$

We do rely on women's own estimation of gestation. We tell women that it's only safe to use the pills until a certain time, after that there is a higher risk.... Sometimes they write to us after they get the pills [to say that their pregnancy is more advanced than nine weeks]. We tell them to take them in the waiting room of a hospital and then it's the same as doing it as a clinic. The protocol changes a little bit. Women are so scared about their health that they might lie, but only a few women will do that. And most women know early. ${ }^{14}$

Second, an important and inevitable limitation of a telemedical abortion service is that it cannot provide aftercare for the small number of women who will require it. While WoW and WHW each offer ongoing support by email, the woman must plan for the possibility that something will go wrong and take responsibility for seeking any necessary further care in that case.

The service stops with being able to provide the early medical abortion. . . . You need to understand limitations of what you can do. If you can't see someone, then you can't measure what a woman means when she says "I have a little bleeding" or a "little pain." The help desk are trained never to attempt an assessment. All they can do is to say that "we can't make an assessment, but if you have this, and this, and this, then you need to see a doctor now." ... We can't replace local health care. You can give information, you can give pills, you can trust women to do it themselves, but if there is a problem, you need the local clinic to assess the situation. ${ }^{15}$

It is important that you repeat to women that they need to have a plan for additional health care if they need it, so that they've thought about it ahead of time. Women tend to be very cautious. They expect the worst. They get instructions, a long list of side effects and potential complications, and they expect that it will probably happen.... Complications are the same for any miscarriage, but ... this is safer than spontaneous miscarriage because you are forewarned. ${ }^{16}$

\footnotetext{
${ }^{13}$ Interview with founding member, WHW.

${ }^{14}$ Interview with Rebecca Gomperts, founder of WoW.

${ }^{15}$ Ibid.

${ }^{16}$ Jelinska, WHW, interview.
} 
Empowerment both allows and relies upon trusting individual women to take a greater degree of control of their own abortions and, more generally, to safeguard their own health.

Privacy is fundamental to a woman's empowerment in this context in two important senses. First, the promise of privacy may be key to opening up the option of home use of pills: were privacy regarding their use not guaranteed, a woman might feel that the option of home use of pills was unavailable to her. Second, privacy reflects an exercise of autonomy, where a person has the choice to divulge or not to divulge information, for whatever set of reasons she finds appealing or convincing (Sanger 2017, 61). Privacy may mean the possibility of ending a pregnancy with no need to justify a decision to professional gatekeepers or to explain one's absence from home, work, or the classroom. One Irish activist explained in an interview that the home use of pills is particularly attractive in a small country, where "it is impossible to fly out of Dublin airport without meeting an acquaintance."

\section{Communities of women}

Abortion pills also open significant possibilities for fostering the power of communities of women to avoid the restrictions on access to services that may be imposed by the state or professional medical gatekeepers. Women across diverse geographical and historical settings have long shared knowledge of fertility control methods (e.g., McLaren 1978, 241; Kaplan 1995; Schiebinger 2008, 158), offering support to each other in more or less formalized ways (e.g., Kaplan 1995). Indeed, the knowledge of local communities of women was key to the development of abortion pills. Having read patient safety leaflets warning against use during pregnancy, women in Brazil began to use and share knowledge about misoprostol (which was available as a treatment for gastric ulcers) as an abortifacient (Arilha and Barbosa 1993).

While practices of solidarity and knowledge sharing in this context are thus both historically and geographically pervasive, they have been revolutionized by the internet. WoW and WHW are international nonprofit collectives, staffed primarily (if not exclusively) by women, motivated by a powerful concern for social justice and working either unpaid or for low salaries. They also promote awareness of the harmful effects of restrictive abortion laws, fight abortion stigma (WHW 2016), and attempt to foster solidarity among the women they support. Each group is funded by a trust-based donation system, with women who can so afford invited to offer $€ 70-€ 90$ (US \$80-\$105) to cover the cost of their own treatment and, where possible, to give more to support services for others. They thus aim to empower com- 
munities and to expand solidarities between women across geographical boundaries. A member of the WoW help desk explained: "Everyone that can give more does give more, even if it's just 5 or 10 euros. Women are very happy to donate money. They connect what's happening to them to the situation of other women. . . . They realize that they are not alone, that the world is full of women in similar situations. Sometimes they write to us that they're inspired to do something ... that they'll make a donation to help another, to spread the word, to join a group locally. Women often write to us, 'I was always against abortion but now I understand.' "17

The empowerment of female communities has a further important corollary: decentering the role of the credentialed medical expert. There is an important difference of emphasis between the two groups here. WHW rejects the need for routine medical oversight:

We have doctors here, but they are for [backup], for the 1-3 percent of the time that the woman has a question that [help desk staff] can't answer. The beauty of the model is empowerment, it's putting control into women's hands. . . . It's one thing when you say a medical professional shares information to empower a patient, but both of them are working within a system where one of them has authority. What we're saying is that this is a procedure that doesn't need that expertise. It's like when one friend helps another to put on a Band-Aid-you don't need a doctor for that. ${ }^{18}$

Rebecca Gomperts, founder of WoW, offers a slightly different view, seeing no tension between the value of empowering women and her work as a doctor, with a desire to work for social justice fundamental to her decision to practice medicine. ${ }^{19}$ However, her vision of the medical relationship - as intrinsically and strongly based on partnership and trust - is a radically nonhierarchical one, diverging sharply from that which has traditionally existed in many formal health-care settings.

Where abortion pills are accessed outside of formal health services, this may affect how their use is viewed. Academic and activist Goretti Horgan suggested to me that women who use abortion pills may not "quite see it as an abortion in the way that they would if they were having to go to a doctor and go through all the medical palaver," noting that this may serve to "reduce any angst" relating to ending a pregnancy. ${ }^{20}$ Activists have attempted

\footnotetext{
${ }^{17}$ Maike, WoW, interview.

${ }^{18}$ Interview with founding member, WHW

${ }^{19}$ Gomperts, WoW, interview.

${ }^{20}$ Interview with Goretti Horgan.
} 
to develop community-based methods of supporting women in home use, through a text- and email-based service. ${ }^{21}$ In neighboring Northern Ireland, they have even considered the creation of a system of "abortion doulas." 22

\section{Stigma and secrecy}

\section{Individual women}

While the home use of abortion pills has done much to enable individual women to bypass restrictive legislation and to seize control of their own fertility, not all women experience this as empowerment. The women surveyed by WoW most commonly reported feeling "relieved" (70 percent) and "satisfied" (36 percent) after their abortions, with women also describing their anger, disappointment, shame, and isolation at not being able to access legal abortion within their own country. Fewer than 10 percent reported having felt "empowered." Further, when abortion services are accessed illegally, this denies the legitimation of legal and medical sanction, thus risking compounding the stigmatization of abortion (Taylor 2015; WHW 2016). As Kinga Jelinska, director of WHW, explained: "The potential of the technology of self-administration of medical abortion [abortion pills] is incredible. It can empower women, and they can do it in the privacy of their own home. It is really revolutionary on many levels. But we also need to acknowledge that, as an individual experience, it is alienating." ${ }^{23}$

Moreover, while home use of abortion pills can offer privacy, this readily collapses into secrecy. While privacy and secrecy may overlap "in purpose, in method, and in ordinary conversation," they are importantly different (Sanger 2017, 61). As Carol Sanger has argued, "secrecy" registers as "more desperate and more necessary," often being "a response to the threat or prospect of harm, whether harassment, stigmatization, loss of one's self-conception, or fear of violence" (Sanger 2017, 61). While fixing the exact motive for nondisclosure in any one instance may be difficult, Sanger's account nonetheless offers an important analytical distinction between privacy and secrecy and grounds a powerful empirical observation that was also borne out in the current study: that abortion concealment in contemporary society aligns not so much with privacy as with secrecy, "a much darker, more psychologically taxing, and socially corrosive phenomenon" (62).

\footnotetext{
${ }^{21}$ For more information, see https://needabortionireland.org/need-abortion-ireland -email-text-support-service/.

${ }^{22}$ Interview with Fiona Bloomer, academic and activist.

${ }^{23}$ Jelinska, WHW, interview.
} 
"Privacy" in home use of pills does not necessarily mean that women are isolated but rather that they have control over who is told about an abortion. Just over three-quarters of those surveyed by WoW were able to talk to family and friends about their abortions. However, that leaves almost one in four lacking this emotional support, and these women were also likely to have the fewest economic resources, suggesting a particularly vulnerable group (Aiken, Gomperts, and Trussell 2017). A member of the WoW help desk staff explained that "women feel much more free to tell us what is happening, to discuss the real situation, to say things that they would never tell their own doctor." However, she immediately went on to note that she also worried about women feeling isolated and having no support, explaining that "we get many emails saying that you're the only one who knows, I can't tell anyone." ${ }^{24}$ While the offer of privacy is thus an important aspect of women's empowerment, this readily blurs into secrecy, which functions as an important brake upon it.

Practices of nondisclosure around abortion are, of course, not a uniquely Irish phenomenon (see, e.g., McLaren 1978; Kaplan 1995; Sanger 2017), nor are they absolute. Irish feminist scholars have worked to disrupt silence around abortion (Rossiter 2009; see also Fletcher 1995), and Irish women have spoken about their own abortions, sometimes at considerable personal cost and often with the explicit aim of helping others and challenging the silence around abortion. Social media has played an increasingly important role in such interventions. ${ }^{25}$ High-profile activist interventions have likewise challenged secrecy regarding abortion, capitalizing on media interest to publicize the existence of abortions pills and where they might be safely obtained. To this end, activists have swallowed pills on a train traveling from Belfast to Dublin (Stack 2014), driven an "abortion bus" around Irish towns (Hayden 2015), and, most recently, delivered pills by drone plane to Northern Ireland (Press Association 2016).

While the secrecy surrounding abortion is thus far from absolute, it is nonetheless significant. After describing her own experience, Irish Times columnist Roisin Ingle writes: "I know there are some women who regret their decisions to have abortions and I understand that must be a terrible pain to carry in their lives. But I also know it has been the right choice for thousands upon thousands of women in Ireland who I hope will not be silenced any longer. Who will, when the time comes, say 'me too' even though that's one of

\footnotetext{
${ }^{24}$ Maike, WoW, interview.

${ }^{25}$ See, e.g., https://www.womenonweb.org/en/page/488/i-had-an-abortion; http:// shareyourabortionstory.tumblr.com/about.html\#sthash.sfUkrH2n.dpuf; and http://www .x-ileproject.com/about/.
} 
the most difficult 'me toos' an Irishwoman can utter" (2015). Another woman recently told a British newspaper that it was only after traveling to England for an abortion that she had discovered that her mother and other close relatives had done the same: "My mum, her cousin, my granny-they've gone for 30 or 40 years and never told anyone. If I'd known about my mum's experience, maybe I could have told her, and maybe it wouldn't have been such an ordeal. To have the moral support would have been great. But none of us feels able to talk about it" (Gentleman 2015). Abortion pills' promise of a private abortion is readily accommodated within this silence, clearly aligning with a more "socially corrosive" secrecy (Sanger 2017, 9).

\section{Communities of women}

The fact that home use of pills is readily accommodated within a more general silence about abortion is also double-edged in broader, societal terms. As the academic and activist Sinéad Kennedy puts it:

Irishwomen travel alone, they can't tell anyone, they live in a veil of secrecy and fear. While I do think that, in many ways, there are a lot of really great things to be said about the abortion pill and how it's made life a lot easier for women, there is also something about it being part of that. The context in which it [abortion] happens matters as well. It's also another way of silencing women, of pushing it to the margins, where they are alone and silenced and can't talk about it. . . That's also something that compounds the experience of isolation and aloneness that characterises the experience of abortion of many women in Ireland. Just not being able to talk about it. [The official line is] “we don't care, as long as you don't tell us about it, we don't really know it's happening."26

The cumulative effect of individual decisions not to speak, in Kennedy's words, can be to "push abortion to the margins," hiding the extent of the harmful consequences of restrictive abortion laws and potentially slowing the momentum for reform (Rossiter 2009).

Finally, while abortion pills offer the potential to empower communities of women, communities have limits, and the networks thus built are inevitably precarious. The empowerment offered by pills is available only to those women who are willing and able to risk flouting the law. Moreover, a focus on securing relief for individual women may result in a desire to avoid rocking the boat or the diversion of attention away from the fight for legal reform

${ }^{26}$ Interview with Sinéad Kennedy. 
and the development of local services. This can operate as an important point of tension within pro-choice communities in the context of ongoing debates about how best to challenge restrictive abortion laws (Culhane 2015). It is also inevitably the case that some women are beyond the reach of WoW and WHW's services. Activists described to me the particular problems faced by women living in "direct provision," where asylum seekers are accommodated by the state in residential institutions (see Thornton 2014). Given restrictions on their travel, these women are generally unable to access services overseas (Fletcher 2005). They are also less likely to have contacts who can share knowledge of abortion pills and how to obtain them, they may lack access to the internet, and even a minor infraction of the law can leave them at risk of deportation.

\section{Official accounts: Silence and ignorance}

Pervasive silence regarding abortion has contributed to an official picture of an Ireland that is nearly abortion free. The Irish government has developed a national strategy, overseen by the Crisis Pregnancy Programme (CPP), to reduce the number of unwanted pregnancies and to support the women experiencing them. Yet the CPP must navigate fine lines within a regulatory framework that understands women who end pregnancies within Ireland as criminals yet those who do the same elsewhere as objects of care and support. Official silence, drawing on what appears to be a carefully cultivated ignorance about abortion, offers one important strategy in negotiating these inherent tensions. Ignorance is not always innocent: it may be strategic, representing "not merely the absence of knowledge but an outcome of cultural struggles" (Schiebinger 2008, 152; see further McGoey 2012a, 2012b). Here, choreographed ignorance and silence regarding the extent and safety of home use of abortion pills and the reliability of those who supply them offers an important strategy for mediating the inherent tensions within a morally incoherent regulatory framework. This official ignorance encompasses the likely extent of home use of abortion pills, the reliability of different suppliers, and the safety of the pills themselves.

\section{Ignorance regarding the extent of illegal home use of pills}

The Irish government claims that "about 4,000 women from Ireland have a termination procedure every year" (CPP n.d.c), admitting a modest amount of uncertainty beyond the numbers recorded in English clinics but failing to acknowledge that substantial numbers are using abortion pills at home. It remains to be seen whether this claim will be revised in the light of the WoW data discussed above (Aiken, Gomperts, and Trussell 2017), but at the time 
of this writing it remains prominently displayed on a government website. There has been no apparent official attempt to disrupt this fiction through the collection of more robust data regarding the extent of home use or women's experience of it. Indeed, maintaining the fiction of an unfeasibly low abortion rate serves a broader political purpose, supporting a positive story of the government's work in combating "crisis pregnancies" and, further, a postcolonial imaginary of a culturally authentic "pro-life" Irishness (Fletcher 2001; see further Smyth 1998, 2005). Ignorance can also have clear advantages in avoiding the repercussions of troubling knowledge: where knowledge has never been brought into existence, it is difficult to hold someone accountable for having failed to act upon it (McGoey 2012a, 559). Notably here, the lack of official knowledge that increasing numbers of women are using abortion pills without apparent significant negative health consequences avoids the need for an official response that moves beyond blanket assertions of the potential dangers of illegal abortion to women's health.

The widespread use of abortion pills also appears to be ignored within the criminal justice system: there have been no prosecutions under Irish abortion law in the past ten years, with only two files relating to illegal abortion considered by Irish prosecutors over that period and just one initial decision to prosecute, which was subsequently withdrawn. ${ }^{27}$ None of my Irish interviewees could foresee a future set of circumstances where a woman would be prosecuted for ending her own pregnancy. Indeed, the CPP advises that women who seek medical aftercare following home use of pills will not be reported to the police, with medical confidentiality protecting them other than in exceptional circumstances (e.g., where there is evidence of abuse; CPP n.d.a, n.d.b). The legal merits of this view are moot (Sheldon 2016), and robust empirical evidence to support it is lacking: the one small relevant study found that 12 percent of hospital doctors would be prepared to report an illegal abortion, with a further 14 percent unsure (Aitken, Patek, and Murphy 2017). However, the advice reflects a more general understanding that, at least with regard to women who have had abortions, the law will remain unenforced.

This lack of prosecutions also reinforces the important official fiction that illegal abortions occur only in small numbers, reflecting the attitude that Kennedy characterized as "we don't care, as long as you don't tell us about it, we don't really know it's happening." ${ }^{28}$ None of the well-publicized ac-

\footnotetext{
${ }^{27}$ Claire Galligan, professional officer, DPP, Ireland, September 22, 2015, letter in response to a request for information under the Freedom of Information Act 2014. On file with author.

${ }^{28}$ Kennedy, interview.
} 
tivist interventions noted above provoked criminal investigation. Indeed, the police who monitored the journey of the "abortion bus" around Ireland were reported as having received instructions merely to look out for public order offenses. Notwithstanding the fact that one woman was reported to have gone home with abortion pills following a Skype consultation with WoW, police apparently considered no more serious action than issuing a parking ticket (Hayden 2015).

\section{Ignorance regarding different sources of pills}

Irish law prohibits the mail order supply of pharmaceuticals, and consignments of abortion pills are regularly impounded at the border (Sheldon 2016). While not wishing to be interviewed for this study, the state agency responsible for the regulation of medicines offered a statement about its work. This statement explained that any supply of pharmaceuticals from outside the "legitimate supply chain" raises potential problems in terms of ensuring the quality or authenticity of medicines (which are of "unknown" quality or may be "falsified or substandard"), the adequacy of information supplied to patients, and the availability of appropriate follow-up medical support in the event of adverse reactions. This is said to create risks to the safety and well-being of the public. ${ }^{29}$ Advice published by the CPP similarly relies on blanket statements regarding the danger of sourcing abortion pills online (CPP n.d.a).

These general claims regarding the dangers of online purchase rely on a studied ignorance of the important differences between various online suppliers. Published, peer-reviewed evidence refutes any suggestion that WoW offers poor-quality or inauthentic medicine, inadequate patient information, or insufficient follow-up (within the limits of a telemedical service, as described above; Gomperts et al. 2008, 2011; Aiken, Gomperts, and Trussell 2017). Moreover, the Irish government has direct, judicial confirmation that WoW's service meets the standards expected of medical practice within another EU state. Apparently at Ireland's instigation, Dr. Rebecca Gomperts of WoW was subject to disciplinary complaint for her activities in prescribing pills from Austria to Irish women. Finding that she had acted within the terms of relevant domestic law, an Austrian court noted that her work made a positive contribution to the health and survival of women in Ireland. ${ }^{30} \mathrm{My}$ own research suggests that WHW is operating to a similar standard.

\footnotetext{
${ }^{29}$ Hugo Bonar, enforcement manager, Health Products Regulatory Agency, personal communication by email, May 25, 2015.

${ }^{30}$ UVS 30.1.2012, UVS-06/9/2829/2010-23, [0]43.
} 
The official silence regarding abortion is also shaped by a specific piece of legislation: the Abortion Information Act. ${ }^{31}$ While the chilling effect of this law has been such that some have misread it as prohibiting the provision of even basic information (Amnesty International 2015), its wording is less restrictive than often supposed. The act allows for the provision of "truthful and objective" information that does not "advocate or promote" abortion, provided that a woman is counseled about "all the courses of action that are open to her" (sec. 5). Specifically, it provides that information may be offered regarding services that "are lawfully available in the place where they are provided ... by persons who are acting lawfully in providing them" (sec. 3). Given that WoW and WHW operate lawfully within the jurisdictions within which they are registered and from which pills are prescribed and supplied, the act would appear to allow for advice to be offered regarding their services. However, current official guidance states that offering such information may be considered to be aiding and abetting the criminal offenses committed by a woman who imports and uses abortion pills (CPP 2015, 9.4.2). While the accuracy of this advice is open to debate (Sheldon 2016), this carefully scripted silence - offering detailed advice regarding what counselors may and may not say (CPP 2015) - leaves women who want to know more about abortion pills reliant on negotiating the mass of information of variable quality available from other sources.

\section{Ignorance regarding clinical evidence}

Finally, official advice to the public (e.g., CPP n.d.a, n.d.b) systematically and significantly overstates the clinical dangers of using abortion pills and the need for medical supervision, in a way that implies ignorance of the substantial clinical evidence base. While this bolsters the case for the criminal prohibition of abortion (suggesting that it can be justified by a concern for women's health as well as in the interests of the "unborn"), it also risks increasing the anxiety of women who use the pills. Claims that abortion pills are "designed to be used in abortion clinics" (CPP n.d.a) ignore the substantial clinical evidence demonstrating that home use is both safe and highly acceptable to women (Kulier et al. 2011; Ngo et al. 2011; Cleland and Smith 2015 ). Advice that "abortion pills should be prescribed only after a face-toface medical consultation in a country where abortion is legal, and taken under medical supervision, where staff can act quickly if complications arise" (CPP n.d.a) disregards the development of legal telemedical delivery protocols in a growing number of settings internationally (Grossman et al. 2011;

${ }^{31}$ Regulation of Information (Services for Termination of Pregnancies) Act (1995). 
Wiebe 2013; Jabour 2015). It also implies that "medical supervision" must involve observation of the woman not merely while she takes the pills but also during her miscarriage (allowing staff to act quickly where necessary). This would require a level of medical oversight that exceeds not merely how abortion pills are used in induced abortions elsewhere in the world but also how misoprostol is used in the management of spontaneous miscarriage within Ireland. The stated need for a face-to-face consultation is likewise not supported by medical evidence (Grossman et al. 2011).

While official discourse thus systematically overplays the dangers of abortion pills, a genuine prioritization of public health would support the provision of accurate information, ensuring that women know how to keep themselves safe (Sheldon 2016). A clear and accurate statement of the medical facts regarding the safety of the home use of pills, however, would potentially risk the appearance of condoning the commission of a serious criminal offense, forcing open the fault line between criminal prohibitions and public health concerns within which the CPP operates. It would also involve treating women as competent decision makers, challenging what one of my interviewees identified as "a tendency in official discourse to view women as helpless and hopeless, with no idea of their own best interests." ${ }^{32}$ Maintaining ignorance regarding the extent and safety of home use offers a potentially useful strategy for papering over this fault line, avoiding the acquisition of the official knowledge that might generate a responsibility to act. A choreographed ignorance regarding abortion can explain the paradox of the appalling suffering inflicted on Ms. Y in the name of upholding the law, on the one hand, and the lack of action taken against the many who flout it, sometimes quite openly, on the other.

Ignorance is not always inevitably and straightforwardly a bad thing (Proctor 2008, 2). Beyond its clear political value to official bodies, the failure to acknowledge the widespread home use of pills in Ireland has carved out a space whereby many women have found a private solution to their unwanted pregnancies, offering significant relief to individuals and important public health benefits to society. This creates an important dilemma for pro-choice activists. Maintaining silence around abortion comes at a heavy cost to women in the Republic. Revealing the extent of home use of pills would highlight that existing law is widely flouted, ineffective, and unfair, most heavily impacting those who lack the resources to travel. However, challenging the official silence also inevitably risks provoking calls to clamp down on illegal abortions or to step up efforts to impede the flow of pills.

${ }^{32}$ Interview with Niall Behan, chief executive IFPA. 


\section{Conclusion}

There is much in the vision with which I opened to tempt those who care about women's reproductive health. The promise of a safe, effective, truly private early abortion method that allows women to bypass repressive state laws and medical control of their fertility is powerful in any context, and ten times more so in one where women's reproductive rights have been so flagrantly disregarded. The availability of abortion pills to women within the Republic of Ireland delivers key aspects of this vision. It has diverted control away from official gatekeepers, directly empowering many individual women and protecting their privacy. Abortion pills have also empowered female communities, fostering mutual support and solidarity. Further, in one sense, whether intended as such or not, each instance of home use constitutes a "political act [of] refusing to submit to various oppressive systems" (WHW 2016).

However, any pro-choice utopian vision that allows states to avoid responsibility for women's reproductive health is, ultimately, an unduly impoverished one. As long as abortion pills are accessed in conditions of secrecy, channels for obtaining them are rendered precarious, and the communities that can be helped are necessarily limited, with particularly vulnerable women falling beyond the reach of the support offered. The privacy offered by the pills readily collapses into a secrecy that speaks less of autonomy and more of necessity. And in resolving their problems in a way that is invisible to official agencies, women's home use of pills has facilitated the continuation of the myth that Ireland is nearly free of abortion, bolstering a carefully choreographed official ignorance and silence regarding its pervasive reality. This distorts public debate, with any intimate connection to abortion "confounded by the reticence of women to speak up and by a failure of imagination (or a reluctance to imagine) by those around them" (Sanger 2017, 68). The veteran pro-choice activist and academic Ailbhe Smyth told me that the Irish referendum giving a strong mandate for the legal recognition of samesex marriage had succeeded because "everyone knows someone who is gay." ${ }^{33}$ Almost certainly, everyone in Ireland also knows a woman who has had an abortion; however, they are far less likely to be aware that this is the case.

Stanley Cohen has described how every personal life and every society is built on denial of the suffering of others, arguing that only an overriding principle - such as social justice - can determine which forms of denial matter and which can be left alone $(2001,295)$. He urges movement beyond those moments when a particular image of suffering creates "a literal wrenching of the heart" - think here of the abused, pregnant child denied

${ }^{33}$ Interview with Ailbhe Smyth. 
the right to access abortion services abroad; the raped asylum seeker denied an abortion; or the seriously ill woman denied necessary medical treatment to complete a spontaneous miscarriage while there is still a fetal heartbeatto a point where knowledge of the suffering that goes on between those times is rendered permanent and continuous, for then "how do we carry on with normal life, knowing what we know?" $(2001,295)$. When the egregious harms caused by the law have been highlighted in the high profile cases of $X$ (Smyth 2005), Ms. Y (Fletcher 2014), and Savita Halvappanavar (HSE 2013; McCarthy 2016), public outrage has erupted onto the streets. Yet while these stories represent countless others that will never be told (Sherlock 2015), the endemic, daily suffering that restrictive laws cause to women within every Irish community remains far more easily ignored. How long then, we might ask, can the struggles of women facing unwanted pregnancy continue to remain tolerable to a society that professes compassion for them?

While they exist in some tension, the twin goals of supporting individual women and challenging repressive laws need not be contradictory. WHW told me: "Activism and safe care are not in opposition. When you talk to women, it doesn't feel like this, it's much more nuanced. If you empower women and support self-administration, you don't take away from advocacy for repealing laws. You need to do both." ${ }^{34}$ This is the ongoing challenge for pro-choice and reproductive health advocates in the run-up to the referendum and beyond it. What is clear is that the genie of fertility control, if ever contained, is now firmly released from the bottle. The development of safe, effective abortion pills means that control cannot easily be snatched back from women's hands.

Kent Law School

University of Kent

\section{References}

Aiken, Abigail, Rebecca Gomperts, and James Trussell. 2017. "Experiences and Characteristics of Women Seeking and Completing At-Home Medical Termination of Pregnancy through Online Telemedicine in Ireland and Northern Ireland: A Population-Based Analysis." British Journal of Obstetrics and Gynaecology 124 (8):1208-15.

Aitken, Kara, Paul Patek, and Mark A. Murphy. 2017. "The Opinions and Experiences of Irish Obstetric and Gynaecology Trainee Doctors in Relation to Abortion Services in Ireland." Journal of Medical Ethics. Prepublished online, March 29. http://jme.bmj.com/content/early/2017/03/29/medethics-2015 -102866.long.

${ }^{34}$ Jelinska, WHW, interview. 
Amnesty International. 2015. "She Is Not a Criminal: The Impact of Ireland's Abortion Law.” Amnesty International, London. http://www.amnestyusa.org /pdfs/Ireland_She_Is_Not_A_Criminal.pdf.

Arilha, Margareth, and Regina Maria Barbosa. 1993. "Cytotec in Brazil: 'At Least It Doesn't Kill.'” Reproductive Health Matters 1(2):41-52.

ASN (Abortion Support Network). 2014. "Abortion Support Network: Annual Report 2014." London: Abortion Support Network. https://www.asn.org.uk /wpcontent/uploads/2011/03/ASN_2014_Annual_Report.pdf.

Bass, Marie. 1998. "Toward Coalition: The Reproductive Health Technologies Project." In Abortion Wars: A Half Century of Struggle, 1950-2000, edited by Rickie Solinger, 251-68. Berkeley: University of California Press.

Baulieu, Étienne-Émile. 1991. The “Abortion Pill." London: Century.

Citizens' Assembly. 2017. "First Report and Recommendations of the Citizens' Assembly: The Eighth Amendment of the Constitution." https://www .citizensassembly.ie/en/The-Eighth-Amendment-of-the-Constitution/Final -Report-on-the-Eighth-Amendment-of-the-Constitution/Final-Report-incl -Appendix-A-D.pdf.

Clarke, Adele, and Theresa Montoni. 1993. "The Many Faces of RU-486: Tales of Situated Knowledges and Technological Contestations." Science, Technology, and Human Values 18(1):42-78.

Cleland, Kelly, Mitchell D. Creinin, Deborah Nucatola, Montsine Nshom, and James Trussell. 2013. "Significant Adverse Events and Outcomes after Medical Abortion." Obstetrics and Gynecology 121(1):166-71.

Cleland, Kelly, and Nicole Smith. 2015. "Aligning Mifepristone Regulation with Evidence: Driving Policy Change Using 15 Years of Excellent Safety Data." Contraception 92(3):179-81.

Cohen, Stanley. 2001. States of Denial: Knowing about Atrocities and Suffering. Malden, MA: Polity.

Cole, Leonard A. 1989. "The End of the Abortion Debate." University of Pennsylvania Law Review 138(1):217-23.

CPP (Crisis Pregnancy Programme). 2015. "Crisis Pregnancy Counselling Skills: A Practice Guide." Health Service Executive Sexual Health and Crisis Pregnancy Programme, Dublin. http://crisispregnancy.ie/crisis-pregnancy-counselling/.

- n.d.a. "Abortion by Tablets or Pills (Medical Abortion)." http://www .positiveoptions.ie/abortion-the-law/what-is-an-abortion-pill/.

_. n.d.b. "Abortion Pill and Medical Supervision." http://www.abortionafter care.ie/abortion-pill.

_. n.d.c. "Post-Abortion Services." http://www.crisispregnancy.ie/crisis -pregnancy-help/post-abortion-services/.

Culhane, Leah. 2015. "Reproductive Justice and the Irish Context: Towards an Egalitarian Framing of Abortion." In The Abortion Papers Ireland, edited by Aideen Quilty, Sinéad Kennedy, and Catherine Conlon, 67-79. Cork: Attic.

Department of Health. 2016. "Abortion Statistics, England and Wales: 2015." Department of Health, London. https://www.gov.uk/government/uploads 
/system/uploads/attachment_data/file/570040/Updated_Abortion_Statistics _2015.pdf.

Fletcher, Ruth. 1995. "Silences: Irish Women and Abortion." Feminist Review 50

(1):44-66.

- 2001. "Post-colonial Fragments: Representations of Abortion in Irish Law and Politics." Journal of Law and Society 28(4):568-89.

- 2005. "Reproducing Irishness: Race, Gender, and Abortion Law." Canadian Journal of Women and the Law 17(2):365-404.

- 2014. "Contesting the Cruel Treatment of Abortion-Seeking Women." Reproductive Health Matters 22(44):10-21.

Gentleman, Amelia. 2015. "It Was the Scariest Thing I've Ever Done': The Irish Women Forced to Travel for Abortions." Guardian, October 31. https://www .theguardian.com/world/2015/oct/31/abortion-ireland-northern-ireland -women-travel-england-amelia-gentleman.

Gomperts, Rebecca, Kinga Jelinska, Susan Davies, Kristina Gemzell-Danielsson, and Gunilla Kleiverda. 2008. "Using Telemedicine for Termination of Pregnancy with Mifepristone and Misoprostol in Settings Where There Is No Access to Safe Services." British Journal of Obstetrics and Gynaecology 115(9):1171-78.

Gomperts, Rebecca, Sabine A. M. Petow, Kinga Jelinska, Louis Steen, Kristina Gemzell-Danielsson, and Gunilla Kleiverda. 2011. "Regional Differences in Surgical Intervention following Medical Termination of Pregnancy Provided by Telemedicine." Acta Obstetricia et Gynecologica Scandinavica 91(2):226-31.

Goodman, Ellen. 1989. "Moral Property.” Boston Globe, July 17, 11.

Grossman, Daniel, Kate Grindlay, Todd Buchacker, Kathleen Lane, and Kelly Blanchard. 2011. "Effectiveness and Acceptability of Medical Abortion Provided through Telemedicine." Obstetrics and Gynecology 118(2):296-303.

Hayden, Sally. 2015. "We Traveled Onboard the Irish 'Abortion Bus' That's Giving Illegal Pills to Women.” Vice News, October 24. https://news.vice.com/article /all-aboard-the-abortion-pill-bus.

HSE (Health Service Executive). 2013. "HSE Publishes Report of the Investigation into the Death of Ms. Savita Halappanavar." June 13. http://www.hse.ie/eng/ser vices/news/media/pressrel/newsarchive/2013archive/junl3/savitareport.html.

Ingle, Róisín. 2015. "Why I Need to Tell My Abortion Story." Irish Times, September 12. http://www.irishtimes.com/life-and-style/people/róis\%C3\%ADn-ingle -why-i-need-to-tell-my-abortion-story-1.2348822.

Jabour, Bridie. 2015. "Abortion Pill RU486 to Be Available to Australian Women over the Phone." Guardian, September 28. https://www.theguardian.com /world/2015/sep/28/abortion-pill-ru486-to-be-available-to-australian-women -over-the-phone.

Kaplan, Laura. 1995. The Story of Jane: The Legendary Underground Feminist Abortion Service. New York: Pantheon.

Kulier, Regina, Nathalie Kapp, A. Metin Gülmezoglu, G. Justus Hofmeyr, Linan Cheng, and Aldo Campana. 2011. "Medical Methods for First Trimester Abortion." Cochrane Database of Systematic Reviews no. 11, art. CD002855. 
Lader, Lawrence. 1992. RU486: The Pill That Could End the Abortion Wars and Why American Women Don't Have It. Reading, MA: Addison-Wesley.

McAvoy, Sandra. 2008. "From Anti-amendment Campaigns to Demanding Reproductive Justice: The Changing Landscape of Abortion Rights Activism in Ireland, 1983-2008." In Schweppe 2008, 15-45.

McCarthy, Joan. 2016. "Reproductive Justice in Ireland: A Feminist Analysis of the Neary and Halappanavar Cases." In Ethical and Legal Debates in Irish Healthcare: Confronting Complexities, edited by Mary Donnelly and Claire Murray, 9-23. Manchester: Manchester University Press.

McDonald, Henry. 2017. "Ireland to Hold Abortion Referendum Weeks before Pope's Visit." Guardian, September 17. https://www.theguardian.com/world /2017/sep/26/ireland-abortion-referendum-pope-visit.

McGoey, Linsey. 2012a. "The Logic of Strategic Ignorance." British Journal of Sociology 63(3):553-76.

- 2012b. "Strategic Unknowns: Towards a Sociology of Ignorance." Economy and Society $41(1): 1-16$.

McLaren, Angus. 1978. Birth Control in Nineteenth-Century England. London: Croom Helm.

Murphy, Mark, Akke Vellinga, Scott Walkin, and Maeve MacDermott. 2012. "Termination of Pregnancy: Attitudes and Clinical Experiences of Irish GPs and GPsin-Training." European Journal of General Practice 18(3):136-42.

Ngo, Thoai D., Min Hae Park, Haleema Shakur, and Caroline Free. 2011. "Comparative Effectiveness, Safety, and Acceptability of Medical Abortion at Home and in a Clinic: A Systematic Review." Bulletin of the World Health Organization 89(5):360-70.

ONS (Office for National Statistics). 2002. Abortion Statistics: Legal Abortions Carried Out under the 1967 Abortion Act in England and Wales, 2001. Series AB no. 28. London: Stationary Office.

Page, Nanette, and Cheryl E. Czuba. 1999. "Empowerment: What Is It?” Journal of Extension 37(5): 5COMl. https://joe.org/joe/1999october/comml.php.

Pollitt, Katha. 2014. Pro: Reclaiming Abortion Rights. New York: Picador.

Prainsack, Barbara, and Alena Buyx. 2011. "Solidarity: Reflections on an Emerging Concept in Bioethics." Nuffield Council on Bioethics, London. http://nuffield bioethics.org/wp-content/uploads/2014/07/Solidarity_report_FINAL.pdf.

Press Association. 2016. "Drone Delivers Abortion Pills to Northern Irish Women." Guardian, June 21. https://www.theguardian.com/uk-news/2016/jun/21 /drone-delivers-abortion-pills-to-northern-irish-women.

Proctor, Robert. 2008. "Agnotology: A Missing Term to Describe the Cultural Production of Ignorance (and Its Study)." In Agnotology: The Making and Unmaking of Ignorance, edited by Robert N. Proctor and Londa Schiebinger, 1-33. Stanford, CA: Stanford University Press.

Raymond, Elizabeth, Caitlin Shannon, Mark A. Weaver, and Beverly Winikoff. 2013. "First-Trimester Medical Abortion with Mifepristone $200 \mathrm{mg}$ and Misoprostol: A Systematic Review.” Contraception 87(1):26-37. 
Rossiter, Ann. 2009. Ireland's Hidden Diaspora: The "Abortion Trail” and Making of a London-Irish Underground, 1980-2000. London: IASC.

Ryan, Orla. 2015. "26 Terminations Carried Out in Ireland under New Abortion Laws." TheJournal.ie, June 29. http://www.thejournal.ie/abortions-ireland -26-2188298-Jun2015/.

Sanger, Carol. 2017. About Abortion: Terminating Pregnancy in Twenty-FirstCentury America. Cambridge, MA: Belknap Press of Harvard University Press.

Schiebinger, Londa. 2008. "West Indian Abortifacients and the Making of Ignorance." In Agnotology: The Making and Unmaking of Ignorance, edited by Robert Proctor and Londa Schiebinger, 149-62. Stanford, CA: Stanford University Press.

Schweppe, Jennifer, ed. 2008. The Unborn Child, Article 40.3.3 and Abortion in Ireland: Twenty-Five Years of Protection? Dublin: Liffey.

Sedgh, Gilda, Jonathan Bearak, Susheela Singh, Akinrinola Bankole, Anna Popinchalk, Bela Ganatra, Clémentine Rossier, Caitlin Gerdts, et al. 2016. “Abortion Incidence between 1990 and 2014: Global, Regional, and Subregional Levels and Trends." Lancet 388(10041):258-67.

Sheldon, Sally. 2016. "How Can a State Control Swallowing? The Home Use of Abortion Pills in Ireland." Reproductive Health Matters 24(48):90-101.

Sherlock, Leslie. 2015. "Towards a Reproductive Justice Model in Ireland." In The Abortion Papers Ireland, edited by Aideen Quilty, Sinéad Kennedy, and Catherine Conlon, 80-89. Cork: Attic.

Smyth, Lisa. 1998. "Narratives of Irishness and the Problem of Abortion: The X Case 1992." Feminist Review 60(1):61-83.

- 2005. Abortion and Nation: The Politics of Reproduction in Contemporary Ireland. Aldershot: Ashgate.

Stack, Sarah. 2014. "Pro-choice Activists Travel on 'Abortion Pill Train' to Belfast." Irish Independent, October 28. http://www.independent.ie/irish-news /prochoice-activists-travel-on-abortion-pill-train-to-belfast-30698655.html.

Taylor, Maeve. 2015. "Abortion Stigma: A Health Service Provider's Perspective." In The Abortion Papers Ireland, edited by Aideen Quilty, Sinéad Kennedy, and Catherine Conlon, 217-27. Cork: Attic.

Thornton, Liam. 2014. "The Rights of Others: Asylum Seekers and Direct Provision in Ireland." Irish Community Development Law Journal 3(2):22-42.

Time. 1993. Cover, June 14. http://content.time.com/time/covers/0,16641 ,19930614,00.html.

UNHRC (United Nations Human Rights Committee). 2016. "Views Adopted by the Committee under Article 5 (4) of the Optional Protocol, concerning Communication No. 2324/2013.” CCPR/C/116/D/2324/2013. June 9, New York. https://www.reproductiverights.org/sites/crr.civicactions.net/files /documents/CCPR-C-116-D-2324-2013-English-cln-auv.pdf.

WHO (World Health Organization). 2011. "Unsafe Abortion: Global and Regional Estimates of the Incidence of Unsafe Abortion and Associated Mortality 
in 2008." 6th ed. World Health Organization, Geneva. http://apps.who.int/iris /bitstream/10665/44529/1/9789241501118_eng.pdf.

_. 2012. "Safe Abortion: Technical and Policy Guidance for Health Systems." 2nd ed. Geneva: World Health Organization. http://apps.who.int/iris/bitstream /10665/70914/1/9789241548434_eng.pdf?ua=1.

_ 2015a. "Health Worker Roles in Providing Safe Abortion Care and Postabortion Contraception." World Health Organization/WHW (Women Help Women), Geneva.

—. 2015b. "WHO Model List of Essential Medicines, 19th List." World Health Organization, Geneva. http://www.who.int/medicines/publications /essentialmedicines/EML_2015_FINAL_amended_NOV2015.pdf ?ua =1 .

WHW (Women Help Women). 2016. "Supporting Independent Use of Abortion Medicines: Fighting Stigma One Email at a Time.” https://womenhelp.org/en /media/inline/2016/5/10/women_help_women_supporting_independent _use_of_abortion_medicines.pdf.

Wiebe, Ellen R. 2013. "Use of Telemedicine for Providing Medical Abortion." International Journal of Gynecology and Obstetrics 124(2):177-78. 